\title{
Severidade de desfolhação e sua influência no intervalo entre cortes, na produtividade e no valor nutritivo do capim-elefante BRS Kurumi
}

\author{
Felipe Jochims ${ }^{1}$ e Aleisson Ludtke ${ }^{2}$
}

\begin{abstract}
Resumo - O uso de forrageiras de alto potencial produtivo ganha importância para elevar os índices produtivos de propriedades rurais sem a elevação dos custos de produção. No entanto, os materiais só expressarão todo seu potencial produtivo se manejados corretamente. Com isso, objetivou-se avaliar diferentes severidades de desfolhação (40, 50, 60 e $70 \%)$ da altura inicial pré-indicada para o capim Kurumi $(80 \mathrm{~cm})$ e os efeitos no intervalo entre cortes, na produtividade e no valor nutritivo. A severidade mais produtiva foi a $50 \%$, produzindo 21 t.ha ${ }^{-1}$ de $M S$, com intervalo entre cortes médio de 18 dias em um período de 155 dias. Esse tratamento também foi superior nos teores de PB $(18,2 \%)$ e na digestibilidade da matéria orgânica $(79,8 \%)$.
\end{abstract}

Termos para indexação: altura; manejo pastagem perene; proteína bruta.

\section{Influence of post-cut residue on cut interval, productivity and nutritional quality of BRS Kurumi elephant grass}

Abstract - The use of grass species with high productive potential became important to increase the productive index of rural proprieties without increasing production costs. However, materials will only express their full productive potential if handled correctly. Thus, the objective was to evaluate different height removal percentages $(40,50,60$ and $70 \%)$ of the initial height pre-indicated for the use of Kurumi grass $(80 \mathrm{~cm})$ and the effects on the cuts interval, productivity and forage nutritional quality. The most productive height removal was 50\%, producing 21 t.ha-1 DM, with an average interval between cuts of 18 days in 155 days. This treatment was also superior in the levels of crude protein (18.2\%) and organic matter digestibility (79.8\%).

Index terms: height; pasture management; crude protein.

\section{Introdução}

O Oeste Catarinense apresentou índices elevados de crescimento na produção leiteira nos últimos anos, sendo atualmente responsável por mais de $79 \%$ do volume de leite produzido no Estado. Além disso, a região também tem apresentado crescimento na concentração de bovinos de corte, com mais de $51 \%$ do rebanho estadual. Desse total, tanto para pecuária de leite quanto para de corte, estima-se que $90 \%$ seja produzido em propriedades familiares, com área média de 16,1ha (JOCHIMS et al., 2016), e com pastagens cultivadas como a principal fonte de alimento dos animais (EPAGRI/CEPA, 2018).

Com essa concentração observa-se que está ocorrendo uma intensificação dos sistemas produtivos, em virtude da necessidade que os produtores têm para se manter no negócio. No entan- to, juntamente com essa intensificação, cresce a necessidade e a exigência quanto à quantidade e qualidade dos alimentos produzidos para os animais, em especial as pastagens de alto potencial produtivo pelo seu menor custo de produção (FREITAS et al., 2019).

Dentre os materiais com alta capacidade produtiva, o capim-elefante BRS Kurumi (Pennisetum purpureum Schum) se destaca pelo seu porte baixo, valor nutricional das folhas e rápido crescimento pós-pastejo ou pós-corte (GOMIDE et al., 2015). No entanto, essas características estão relacionadas diretamente ao manejo da cultura, com destaque para o momento correto de utilização e, principalmente, ao resíduo deixado no momento da saída dos animais ou após o corte (SILVA et al., 2015).

A produtividade máxima do pasto, independentemente do seu potencial produtivo, se dá por uma combinação de fatores. Por exemplo, o melhor momento para se iniciar a utilização é um deles e se dá quando a pastagem está em sua máxima produtividade líquida (folhas verdes), sem perdas de forragem por senescência e alongamento de colmos. Isso ocorre quando não mais que $95 \%$ da radiação fotossinteticamente ativa está sendo interceptada pelo dossel forrageiro (CHAVES et al., 2016). Para o capim Kurumi, essa condição é obtida com aproximadamente $80 \mathrm{~cm}$ de altura (GOMIDE et al., 2015). O outro fator, a velocidade de crescimento após o pastejo, irá depender da quantidade de folhas fotossinteticamente ativas que são mantidas no resíduo. Para um rápido rebrote se recomenda a manutenção de uma área foliar residual (CHAPMAN, 2016), o que ocorre quando se remove em torno de $60 \%$ da altura do dossel forrageiro. Ambas as variáveis podem ser manejadas e controladas utilizan-

Recebido em 6/4/2020. Aceito para publicação em 1/6/2020.

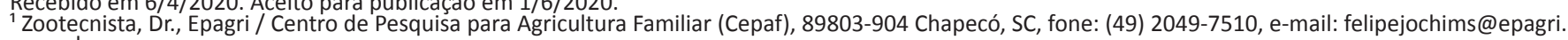

gov.sc.br. 
do a altura do dossel forrageiro, tendo em vista a relação direta entre massa de forragem com a altura que ela apresenta (HODGSON, 1990), embora esse, provavelmente, ainda seja o maior erro de manejo cometido pelos manejadores, fazendo com que as pastagens produzam muito aquém do seu potencial genético.

Outro fator que influencia a produtividade animal é o valor nutritivo da forragem ingerida. Essa característica pode influenciar diretamente na limitação do consumo dos animais, seja pela estrutura formada no dossel da pastagem (CARVALHO, 2013), seja pela fibrosidade e a baixa degradação ruminal do ingerido, ou ainda por ser deficiente quanto aos teores de proteína bruta (VAN SOEST, 1991) por exemplo, o que causaria baixas produtividades e a necessidade de incrementar a dieta com alimentos concentrados, elevando o custo com a alimentação. Esse valor nutritivo da forragem está diretamente relacionado com as variáveis produtivas. De forma geral, quanto menor a quantidade de colmos e folhas em senescência colhida pelos animais, maior será o valor nutritivo da forragem consumida pelo animal. Isso é controlado pelo manejador ao oferecer as pastagens manejadas corretamente, com alta quantidade de folhas, aos animais. Nas folhas os nutrientes têm uma menor diluição em relação a outros componentes da planta (LEMAIRE et al., 2008).

Dessa forma, o objetivo do presente trabalho foi avaliar o efeito de diferentes severidades de desfolhação, de 40 a $70 \%$ da altura de manejo pré-recomendada (80cm; GOMIDE et al., 2015) em uma pastagem de capim BRS Kurumi, no intervalo entre cortes, produtividade e no valor nutricional da pastagem.

\section{Material e métodos}

O presente experimento foi conduzido em uma propriedade rural, localizada no município de Iporã do Oeste, SC, sob coordenadas $26^{\circ} 58^{\prime} 53.72$ " Sul e $53^{\circ} 32^{\prime} 15.32^{\prime \prime}$ Oeste, com 556 metros de altitude, entre 2018 e 2019 . O clima da região é classificado como Mesotér- mico Brando, com temperatura média das máximas diárias entre 27 e 28 드, e média das mínimas entre 13 e 14 ํㅡ, com precipitação total anual variando de 1700 a $1900 \mathrm{~mm}$ e umidade relativa de $78 \%$ (BRAGA, 1999).

$A$ área experimental compreendia $400 \mathrm{~m}^{2}$ onde foram implantadas 16 parcelas de $4 \times 3 \mathrm{~m}$ com capim elefante anão Pennisetum purpureum Schum, cv. BRS Kurumi. As parcelas foram implantadas utilizando-se mudas de capim Kurumi em um espaçamento de $0,5 \times 0,5 \mathrm{~m}$. Devido à declividade do terreno, o delineamento experimental utilizado foi em blocos ao acaso, com 4 tratamentos e 4 repetições. $O$ solo da área é classificado como Latossolo e apresentou as seguintes características químicas na camada de 0 a 20cm: \% Argila m/v: 50; pH-Água 1:1: 5,3; Índice SMP: 6,1; P (mg dm$\left.{ }^{-3}\right)$ : 12,2; $\mathrm{K}\left(\mathrm{mg} \mathrm{dm}^{-3}\right): 96,8 ; \%$ M.O. m/v: 4,8; Al cmolc dm${ }^{-3}$ : 0,4; Ca (cmolc dm $\left.{ }^{-3}\right): 7,2$; $\mathrm{Mg}\left(\mathrm{cmolc} \mathrm{dm}^{-3}\right): 4,2 ; \mathrm{H}+\mathrm{Al}\left(\mathrm{cmolc} \mathrm{dm}^{-3}\right)$ : 3,98; CTC pH 7.0 (cmolc dm ${ }^{-3}$ ): 15,65; \% Saturação de Bases (CTC pH 7,0): 74,57.

Com base nas características químicas do solo foi realizada a correção para um $\mathrm{pH}$ de referência 6,0 com calcário dolomítico incorporado por meio de gradagens 33 dias prévios ao transplante das mudas. Os níveis de fósforo foram corrigidos na mesma operação, com fertilizante Superfosfato Triplo, na dose de $210 \mathrm{~kg} \mathrm{ha}^{-1}$. A adubação realizada na área seguiu a recomendação do Manual de Adubação e Calagem (ROLAS, 2016) para gramíneas forrageiras perenes, estabelecendo uma expectativa de produtividade de $18 \mathrm{t} \mathrm{ha}^{-1}$ de matéria seca (MS). Assim, um total de $300 \mathrm{~kg} \mathrm{ha}^{-1}$ de $\mathrm{N}$ na forma de ureia foi aplicado de maneira parcelada, em seis ocasiões, entre setembro de 2018 e abril de 2019, totalizando 155 dias de avaliação.

Os tratamentos experimentais consistiram aplicar diferentes severidades de desfolhação, removendo $40 \%, 50 \%$, $60 \%$ e $70 \%$ da altura do dossel da pastagem, utilizando uma altura pré-determinada de $80 \mathrm{~cm}$ para a utilização (entrada) (GOMIDE et al., 2015). As alturas residuais resultantes dessas desfolhações, que constituíam os tratamentos, foram de 48,40 , 32 e $24 \mathrm{~cm}$, seguindo as por- centagens de remoção descritas acima, respectivamente.

As avaliações de alturas eram realizadas diariamente, em 15 pontos por parcela, utilizando um bastão graduado em centímetros (sward-stick). A altura da parcela era a média de 15 pontos amostrados e a altura do tratamento era a média de suas quatro repetições. A cada vez que a média da altura das repetições de cada tratamento atingia $80 \mathrm{~cm}$, o tratamento era coletado (as quatro repetições). Os cortes entre os tratamentos poderiam se dar em datas diferentes, pois a velocidade de crescimento dos diferentes tratamentos poderia ser diferente. $\mathrm{A}$ área útil das avaliações foi de $1,5 \mathrm{~m}^{2}$, no centro da parcela e o material foi cortado com tesouras manuais de tosquia seguindo as alturas residuais pré-determinadas pelo protocolo experimental.

Após o corte as amostras foram pesadas e secas em estufa com circulação forçada de ar a $60^{\circ} \mathrm{C}$, até atingirem peso constante (aproximadamente 96 horas). Após, as amostras foram pesadas novamente para mensuração dos teores de matéria seca e posterior cálculo da massa de forragem em (kg MS ha-1). Como os dados foram avaliados diariamente e cada tratamento apresentou tempo distinto para a recomposição da biomassa aérea, avaliou-se o intervalo entre cortes (em dias).

Nos cortes realizados no dia $22 / 11 / 2018$ e próximo aos dias 08/02/2019 e 10/04/2019 foram feitas subamostras a partir do material colhido na avaliação da massa de foragem, para análises de qualidade em laboratório. Exceto no dia $22 / 11$, as demais amostras não são provenientes do mesmo dia devido às diferenças nas datas dos cortes dos diferentes tratamentos, ainda assim, o estádio fisiológico das plantas era semelhante entre os diferentes rebaixamentos. As subamostras foram misturadas para compor amostras representativas de cada tratamento, as quais foram analisadas no laboratório de nutrição animal da Epagri, na Estação Experimental de Lages, SC. As variáveis analisadas foram o teor de proteína bruta (PB; N x 6,25) de acordo com pro-॰ 
cedimento descrito em AOAC (1997), fibra em detergente neutro e ácido (FDN e FDA, respectivamente) de acordo com Senger et al. (2008) e a digestibilidade in vitro da matéria seca (DIVMS) e da matéria orgânica (DIVMO), seguindo metodologia descrita por Tilley \& Terry (1963).

Os resultados do estudo foram submetidos à análise de variância, considerando o delineamento em blocos casualizados em esquema de parcelas subdivididas, com alturas de corte como tratamento principal (parcela) e os diferentes cortes como tratamentos secundários (subparcela). Quando foi realizada a soma dos cortes no ano, considerou-se apenas o fator altura de corte. Em todas as situações, as pressuposições de homogeneidade de variâncias e distribuição normal dos resíduos foram verificadas. Após o atendimento das pressuposições, as inferências da análise de variância foram realizadas e, em casos significativos como os efeitos de fatores, as médias foram comparadas pelo teste de Tukey. Todas as análises foram realizadas com o ambiente $R$ (2016), adotando o nível de $5 \%$ de significância.

\section{Resultados e discussão}

As diferentes severidades de desfoIhação da massa de forragem influenciaram no intervalo, em dias, entre os cortes da pastagem e, consequentemente, no número total de cortes realizados ao longo do período de avaliação do Capim BRS Kurumi (Tabela 1). Conforme aumentou a remoção da altura do dossel, mantendo um resíduo menor, maior foi o intervalo entre os cortes, que é o tempo para a recuperação da altura para o próximo corte.

Quando a intensidade de desfolha foi de $70 \%$, o intervalo entre cortes foi de, em média, 25 dias. Esse período representa $42 \%$ mais tempo quando comparado com a intensidade de $40 \%$, $27,1 \%$ mais tempo do que a intensidade de $50 \%$ e $10,6 \%$ mais tempo que a intensidade de $60 \%$, os quais foram de 15,18 e 22 dias, respectivamente. Esses diferentes intervalos geraram diferen-
Tabela 1. Número de cortes, produção de massa de forragem por corte e total ( $\mathrm{kg} \mathrm{ha}^{-1} \mathrm{de}$ MS) de capim BRS Kurumi manejado com intensidades de desfolhação de 40 a $70 \%$ da altura inicial de $80 \mathrm{~cm}$ ao longo de 155 dias. Iporã do Oeste, SC, 22/11/2018 a 26/04/2019 Table 1. Number of cuts, total and per cut herbage mass production ( $\mathrm{kg} \mathrm{ha}^{-1}$ of DM) from BRS Kurumi grass managed under defoliation intensities varying from 40 to $70 \%$ of $80 \mathrm{~cm}$ initial height over 155 days. Iporã do Oeste, SC, 22/11/2018 a 26/04/2019

\begin{tabular}{|c|c|c|c|c|}
\hline \multirow[t]{2}{*}{ Número do corte } & \multicolumn{4}{|c|}{ Intensidade de desfolha ${ }^{1}$} \\
\hline & $70 \%$ & $60 \%$ & $50 \%$ & $40 \%$ \\
\hline 1 & $2402^{\mathrm{a}}{ }_{\mathrm{c}}$ & $2119^{a}$ & $1795^{\mathrm{ab}}$ & $1320^{b}{ }_{A B}$ \\
\hline 2 & $2666^{\mathrm{a}}{ }_{\mathrm{BC}}$ & $2047^{\mathrm{ab}}$ & $1535^{\mathrm{b}}{ }_{\mathrm{c}}$ & $843^{c}$ \\
\hline 3 & $3191_{A B}^{a}$ & $2259^{b}$ & $2645^{\mathrm{ab}}$ & $1661_{A B}^{c}$ \\
\hline 4 & $3083^{a}{ }_{A B}$ & $2332^{b}$ & $2547_{A B}^{a b}$ & $1686^{c}$ \\
\hline 5 & $2973^{a}{ }_{A B C}$ & $2413^{a}{ }_{A B}$ & $2641_{A}^{a}$ & $1544^{\mathrm{b}}{ }_{\mathrm{AB}}$ \\
\hline 6 & $3510_{A}^{a}$ & $2733^{b}{ }_{A B}$ & $2136_{A B}^{b}$ & $1756_{A}^{c}$ \\
\hline 7 & - & $3124^{a}$ & $2742^{a}{ }_{A}$ & $1278^{b}{ }_{A B}$ \\
\hline 8 & - & $2723^{a}{ }_{A B}$ & $2621_{A}^{a}$ & $1649^{b}{ }_{A B}$ \\
\hline 9 & - & - & $2410^{\mathrm{a}}{ }_{\mathrm{AB}}$ & $1682^{b}{ }_{A}$ \\
\hline 10 & - & - & - & $2045^{a}{ }_{A}$ \\
\hline 11 & - & - & - & $1880_{A}^{a}$ \\
\hline Produção TOTAL & $17.825^{c}$ & $19.751^{b}$ & $21.070^{a}$ & $17.343^{c}$ \\
\hline Dias entre cortes & 25,4 & 22,7 & 18,5 & 14,7 \\
\hline Coef. Variação (\%) & & $18,8^{*}$ & $6,04^{\#}$ & \\
\hline Significâncias ( $P=)$ & & $0,003^{2}$ & $0,001^{3}$ & \\
\hline
\end{tabular}

${ }^{17} 70 \%=80$ a $24 \mathrm{~cm} ; 60 \%=80$ a $32 \mathrm{~cm} ; 50 \%=80$ a $40 \mathrm{~cm} ; 40 \%=80$ a $48 \mathrm{~cm} ;{ }^{*} \mathrm{CV}$ cortes; ${ }^{\#} \mathrm{CV}$ prod. total; ${ }^{2}$ interação tratamento $\mathrm{x}$ corte; ${ }^{3} \mathrm{P}$ value para produção total

Médias seguidas por letras minúsculas sobrescritas diferentes na linha diferem entre si pelo teste de Tukey a $5 \%$ de probabilidade.

Médias seguidas por letras maiúsculas subscritas diferentes na coluna diferem entre si pelo teste de Tukey a $5 \%$ de probabilidade.

tes números de cortes. A intensidade de $70 \%$ gerou 6 cortes, enquanto as intensidades de 60, 50 e $40 \%$ geraram 8,9 e 11 cortes, respectivamente.

O tempo de recuperação da altura se dá por dois motivos: menor fitomassa para recuperar nas menores intensidades de rebaixamento e índice de área foliar do resíduo, quando as plantas mantêm a fotossíntese ativa, mantendo um ritmo de crescimento elevado mesmo com o distúrbio (pastejo ou corte), além de não mobilizar suas reservas para o novo crescimento (CHAPMAN \& LEMAIRE, 1993).

Apesar do maior número de cortes obtido no tratamento com baixa remoção de forragem (severidade de $40 \%$ ), a produtividade total de forragem não foi a mais elevada (Tabela 1). Isso se deve ao peso baixo de cada colheita e, mesmo que colhido diversas vezes (11), não resultou em uma maior produtividade ou produção colhida. Além disso, a densidade de forragem dos estratos intermediários desse tratamento pode ter sido inferior aos demais, especialmente pelo baixo estímulo na produção de perfilhos aéreos, causado pela baixa "decapitação" de meristemas na intensidade baixa de desfolhação (SBRISSIA et al., 2018). 
Houve interação $(P<0,05)$ tratamento $\times$ corte na produção de massa de forragem (Tabela 1). Boa parte dessas diferenças se deve ao próprio protocolo experimental. Como os tratamentos consistiram da remoção de diferentes proporções da altura do dossel forrageiro, e existe uma correlação direta entre altura e massa (HODGSON, 1990), maiores massas de forragem foram removidas com maiores severidades de desfoIhação. Os tratamentos com intensidade de desfolha mais intensa (70 e 60\%) apresentaram maior massa de forragem por corte, pois uma quantidade maior de massa foi removida na avaliação. Isso pode ser devido ao grande número de perfilhos gerados nesses tratamentos ao longo do tempo, aumentando a densidade de folhas na parte aérea do dossel da pastagem (SBRISSIA et al., 2018).

De modo geral, quanto maior a altura removida, maior é a massa de forragem do corte. No entanto, essa estratégia pode implicar um maior tempo de recuperação da pastagem para a próxima utilização e, consequentemente, afetar o número de cortes, confirman- do o sugerido por Parson et al. (1988). O somatório de todos os cortes determina a produção total de forragem e, mesmo com massas menores por corte, o aumento do número de cortes pode aumentar a produção total de forragem. Essa resposta, na realidade, faz com que as comparações entre os cortes dos tratamentos seja de difícil execução, pois a colheita da foragem em métodos de lotação intermitente invariavelmente irá gerar diferentes datas pré-corte se diferentes manejos forem aplicados.

Por exemplo, o quarto corte do tratamento com severidade de desfolha de $70 \%$ foi realizado no 63임 19 dias a mais em relação a data do quarto corte do tratamento com severidade de $40 \%$, o qual foi realizado no 44으 dia. Assim, para facilitar o entendimento, os dados serão apresentados de forma gráfica (Figura 1). Observa-se que a dinâmica de acúmulo de forragem nas diferentes severidades de desfolha é diferente e ocorrem em datas distintas, resultado direto do manejo aplicado na pastagem, e é capaz de demonstrar a importância da manutenção de um resíduo com

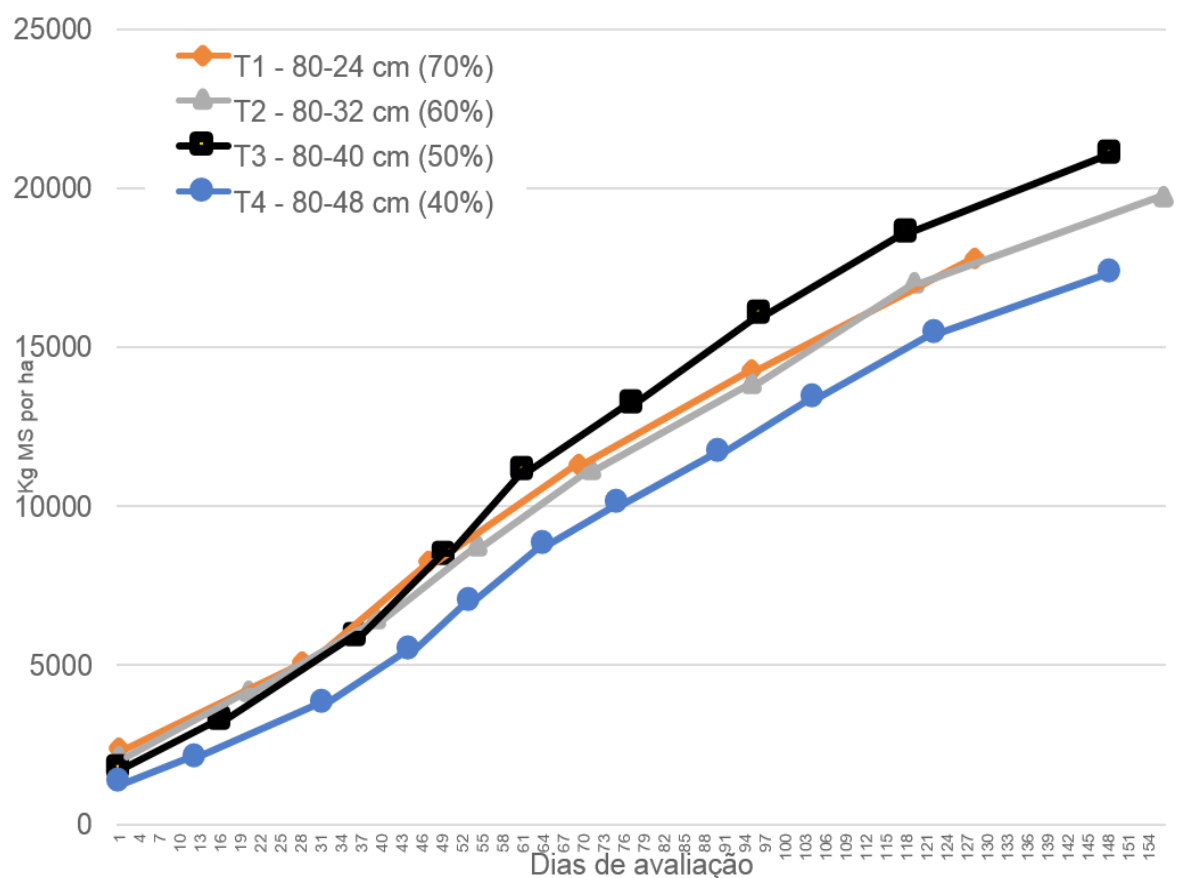

Figura 1. Evolução do acúmulo de massa $\left(\mathrm{kg} \mathrm{MS} \mathrm{ha}^{-1}\right)$ e intervalo entre cortes de capim BRS Kurumi manejado com níveis de remoção de biomassa de 40 a 70 \% da altura inicial de 80 $\mathrm{cm}$ ao longo de 155 dias. Iporã do Oeste, SC, 22/11/2018 a 26/04/2019

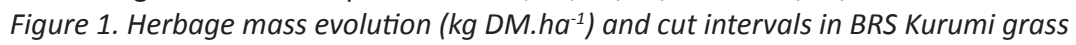
managed with defoliation intensities varying from 40 to $70 \%$ of $80 \mathrm{~cm}$ initial height over 155 days. Iporã do Oeste, SC, 22/11/2018 a 26/04/2019 folhas verdes no dossel da pastagem, confirmando o já descrito na literatura (BARBERO et al., 2015).

Quanto à variação de produção de massa de forragem entre os cortes dentro da mesma severidade de desfolhação, elas ocorrem devido ao ciclo produtivo da espécie (perene de verão) e à influência climática com o passar do tempo. As diferenças podem ser observadas nas quatro severidades.

As maiores produtividades foram observadas quando o rebaixamento foi de $50 \%$ da altura do dossel da pastagem. Esse tratamento rendeu nove colheitas, em média uma a cada 18,5 dias, produzindo um total de $21.070 \mathrm{~kg}$ de $\mathrm{MS} \mathrm{ha}^{-1}$ em 155 dias. Com produção total $7 \%$ inferior $(P<0,05)$, rebaixando $60 \%$ da altura, a produtividade foi de $19.751 \mathrm{~kg}$ de $\mathrm{MS} \mathrm{ha}{ }^{-1}$, com oito cortes e 22,7 dias de intervalo entre os cortes. Rebaixamento de 40\%, apesar de gerar 11 cortes, um a cada 14,7 dias em média, apresentou uma produtividade $17 \%$ inferior às remoções de 50 e $60 \%$, totalizando $17.343 \mathrm{~kg}$ de $\mathrm{MS} \mathrm{ha}^{-1}$. Essa produção menor é igual $(P>0,05)$ aos resultados obtidos com rebaixamento de $70 \%$ da altura do dossel, apesar desse tratamento com maiores remoções ter gerado seis cortes, com intervalo médio de 25,4 dias. Os valores de produção estão de acordo com os poucos dados encontrados na literatura sobre esse cultivar (GOMIDE et al., 2015).

Esses tratamentos apresentam produtividade menor por motivos distintos. As remoções mais severas com $70 \%$ de rebaixamento deixam baixo resíduo de folhas no resíduo, prejudicando o rebrote pela baixa captação de radiação solar, no entanto, as massas dos cortes são altas pela alta proporção de colmos no material coletado (ARAUJO et al., 2011). Ao contrário, a baixa remoção do tratamento de $40 \%$, mesmo com alto resíduo de folhas e rápido crescimento, não estimulou o perfilhamento do Kurumi, ocasionando menor densidade de perfilhos e consequentemente de folhas na parte aérea (BARBERO et al., 2015). Acrescido a isso, os cortes são leves por apresentarem somente "pontas" de folhas na massa cortada, a qual tem menor teor de MS e menor massa. 
Tabela 2. Teores de proteína bruta (\%), fibra em detergente neutro (FDN), fibra em detergente ácido (FDA), em \%, digestibilidade in vitro da matéria seca (DIVMS) e da matéria orgânica (DIVMO) de capim BRS Kurumi manejado com diferentes intensidades de desfolhação, de 40 a $70 \%$ da altura inicial de $80 \mathrm{~cm}$, ao longo de 155 dias. Iporã do Oeste, SC, 22/11/2018 a 26/04/2019

Table 2. Crude protein (\%), neutral detergent fiber (FDN), acid detergent fiber (FDA), in \%, in vitro dry matter and organic matter digestibility of BRS Kurumi grass managed with defoliation intensities varying from 40 to $70 \%$ of $80 \mathrm{~cm}$ initial height over 155 days. Iporã do Oeste, SC, $22 / 11 / 2018$ a $26 / 04 / 2019$

\begin{tabular}{lcccccc}
\hline $\begin{array}{c}\text { Entrada -Saída } \\
(\mathbf{c m})\end{array}$ & $\begin{array}{c}\text { Intensidade de } \\
\text { desfolha (\%) }\end{array}$ & PB & FDN & FDA & DIVMS (\%) & DIVMO (\%) \\
\hline $80-48$ & 40 & $18,86^{\mathrm{A}}$ & $56,15^{\mathrm{B}}$ & $29,02^{\mathrm{B}}$ & $70,75^{\mathrm{A}}$ & $80,35^{\mathrm{A}}$ \\
\hline $80-40$ & 50 & $18,18^{\mathrm{A}}$ & $57,75^{\mathrm{A}}$ & $30,80^{\mathrm{A}}$ & $71,36^{\mathrm{A}}$ & $79,81^{\mathrm{AB}}$ \\
\hline $80-32$ & 60 & $17,33^{\mathrm{A}}$ & $56,83^{\mathrm{AB}}$ & $31,48^{\mathrm{A}}$ & $70,19^{\mathrm{A}}$ & $78,97^{\mathrm{B}}$ \\
\hline $80-24$ & 70 & $14,22^{\mathrm{B}}$ & $55,17^{\mathrm{C}}$ & $29,73^{\mathrm{B}}$ & $68,54^{\mathrm{B}}$ & $77,85^{\mathrm{C}}$ \\
\hline Coef. Variação (\%) & & 5,44 & 0,74 & 1,01 & 1,33 & 1,23 \\
\hline Significância (P=) & & 0,003 & 0,001 & $<0,001$ & 0,044 & 0,044 \\
\hline
\end{tabular}

Médias seguidas por letras sobrescritas diferentes na linha diferem entre si pelo teste de Tukey a $5 \%$ de probabilidade.

As diferentes severidades de desfoIhação utilizadas no momento dos cortes influenciaram diretamente o valor nutritivo do capim Kurumi colhido (Tabela 2). As severidades de 40, 50 e $60 \%$ não diferem entre si $(P>0,05)$ quanto ao teor de proteína bruta e foram superiores $(P<0,05)$ em $21 \%$ ao tratamento com severidade de $70 \%$ da altura. Esse resultado é observado pela maior proporção de colmos na amostra quando a remoção é elevada, o que dilui a concentração de $\mathrm{N}$, que é abundante apenas nas folhas das pastagens (LEMAIRE \& GASTAL, 2007). Esse resultado também demonstra a importância de manejar a pastagem para que animais tenham acesso a somente folhas, uma vez que, além de elevar o consumo, o valor nutritivo do material colhido também será maior, proporcionando elevados desempenhos.

As frações fibrosas da pastagem (FDN e FDA), que representam os constituintes da parede celular, em especial celulose, hemicelulose e lignina, diferiram $(P<0,05)$ entre as severidades. Rebaixamentos de 40, 50 e 60\% apresentaram-se superiores em relação à quantidade de fibra, o que é, de certa forma, contraditório. A severidade de $70 \%$ apresentou os menores teores de FDN, algo em torno de 3\% (Tabela 2), mesmo, teoricamente, com a maior concentração de colmos no colhido. Como o teor de fibra tem relação com a parte estrutural das plantas (VAN SOEST et al., 1991), o tratamento com mais colmo deveria apresentar teores mais elevados de fibra (CHAVES et al., 2016). Essa diferença observada pode ser devida a um aumento na quantidade de perfilhos aéreos nas severidades de desfolhação baixas, fazendo com que colmos acabassem entrando nas amostras (SBRISSIA et al., 2018). De qualquer modo, os teores de FDN são considerados bons para plantas estivais em todas as intensidades (VAN SOEST, 1991).

O mesmo ocorreu para os teores de FDA. Como a FDA é uma "continuação laboratorial" do FDN na análise, sendo somente a celulose e a lignina, o resultado inesperado se manteve. Os tratamentos com severidade de 40 e $70 \%$ tiveram resultados $5,6 \%$ inferiores de FDA quando comparados com as severidades de 50 e $60 \%$.

Os teores de digestibilidade já apresentaram resultados dentro do hipotetizado, tanto para a digestibilidade in vitro da matéria seca (DIVMS) quanto da matéria orgânica (DIVMO). Para essas variáveis, quanto maior a quantidade de folhas na amostra, maior a DIVMS e DIVMO, o que realmente foi observado nos resultados. A DIVMS dos rebaixamentos 40,50 e $60 \%$ foram semelhan- tes $(P>0,05)$ e diferiram em $4 \%$ a DIVMS do tratamento com rebaixamento de $70 \%$. Essa redução na taxa de digestibilidade se deve à inclusão de colmos, material com mais lignina, nas amostras. Já para a DIVMO, os rebaixamentos 40 e $50 \%$ foram $1,5 \%$ superiores $(P<0,05)$ ao rebaixamento de $60 \%$ da altura e $3 \%$ superior $(P<0,05)$ ao rebaixamento de $70 \%$.

Com isso e, considerando características qualitativas da pastagem, se observa que o rebaixamento que utiliza a parte estrutural da pastagem, como os colmos, reduz o valor nutritivo do material ofertado aos animais, em especial a proteína bruta. Pastagens manejadas nas alturas indicadas na literatura, removendo somente a parte superior do dossel certamente irão proporcionar melhores produções e consequentemente, melhores desempenhos dos animais.

As implicações práticas desses resultados são que, quanto menor a remoção de massa de forragem, mais rápido será a recuperação da altura do dossel, gerando um maior número de cortes. No entanto, o maior número de cortes não implica maiores produtividades nem cortes pesados. A maior produtividade observada no capim BRS Kurumi ocorre quando a pastagem é manejada utilizando $50 \%$ da altura de entrada pré- 
definida, que é de $80 \mathrm{~cm}$. Dessa forma, em 155 dias o Kurumi apresentou produção total média de 20,5 toneladas de MS e tempo de rebrote médio de 20 dias, considerando as intensidades de 50 e $60 \%$. Além disso, esses tratamentos também concentraram os melhores índices de qualidade nutricional da pastagem, especialmente pela quantidade de folhas nas amostras.

\section{Conclusões}

A severidade de desfolhação influencia a produtividade, o intervalo entre cortes e o valor nutritivo do capimelefante BRS Kurumi;

A severidade mais produtiva foi a $50 \%$, produzindo $21 \mathrm{t} \mathrm{ha}{ }^{-1}$ de $\mathrm{MS}$, com teores superiores de proteína bruta de $18 \%$ e de digestibilidade de matéria orgânica de $80 \%$.

\section{Referências}

ARAUJO, S.A.C.; VASQUEZ, H.M.; SILVA, J.F.C.; LIMA, E.S.; LISTA, F.N.; DEMINICS, B.B.; CAMPOS, P.R.S.S. Produção de matéria seca e composição bromatológica de genótipos de capim-elefante anão. Archivos de Zootecnia, Córdoba , v.60, n.229, p.83-91, 2011.

ASSOCIATION OF OFFICIAL ANALYTICAL CHEMISTS (AOAC). Official methods of analysis. Gaithersburg, MD, 1997. 1298p.

BARBERO, L.M.; BASSO, K.C.; IGARASI, M.S.; PAIVA, A.J.; BASSO, F.C. Respostas morfogênicas e estruturais de plantas tropicais submetidas à desfolhação. Boletim de Indústria Animal, v.72, n.4, p.321-330, 2015. DOI: http://dx.doi.org/10.17523/bia.v72n4p321.

BRAGA, H.J. Proposta de diferenciação climática para o Estado de Santa Catarina. In: Congresso Brasileiro De Agrometeorologia, 11. Reunião Latino Americana De Agrometeorologia, 2., 1999, Florianópolis, SC. Anais[...] Florianopolis: Epagri, 1999. 1 CDROM.

CARVALHO, P.C.F. Can grazing behavior support innovations in grassland management? Tropical Grasslands v.1, p.137-155, 2013.

CHAPMAN, D.F.; LEMAIRE, G. Morphogenetic and structural determinants of plant regrowth after defoliation. In: Baker, M.J. (Ed.). Grasslands for our world. Wellington: Sir Publishing p. 55-64, 1993.

CHAVES, C.S.; RIBEIRO, K.G.; GOMIDE, C.A.M.; PACIULO, D.S.C.; MORENZ, M.J.F.; GAMA, D.S. Valor nutritivo e cinética de degradação in vitro de genótipos de capimelefante (Penissetum purpureum Schumach) sob dois intervalos de desfolhação e duas alturas de resíduo pós-pastejo. Arq. Bras. Med. Vet. Zootec., v.68, n.5, p.1351-1359, 2016.

SILVA, S.C., SBRISSIA, A.F., PEREIRA, L.E.T. Ecophysiology of $\mathrm{C} 4$ forage grasses-understanding plant growth for optimising their use and management. Agriculture, v.5, p.598-625, 2015.

EPAGRI/CEPA. Síntese Anual da Agricultura de Santa Catarina - 2017 - 2018. Florianópolis, SC. 2018.

FREITAS, P.F.V.X.; TOMAZELLO, D.A.; RIBEIRO, F.M.; OLIVEIRA, J.F.A.; LOPES, A.R.; ALMEIDA, E.M.; NETO, C.M.S.; FRANÇA, A.F.S. Efeitos do pastejo no desenvolvimento e crescimento de plantas forrageiras. Revista Científica Rural, v.21, n.2, 2019. DOI: https://doi. org/10.30945/rcr-v21i2.2776

GOMIDE, C.A.M.; PACIULLO, D.S.C.; LEDO, F.J.S.; PEREIRA, A.V.; MORENZ, M.J.F.; BRIGHENTI, A.M. Informações sobre a cultivar de capim-elefante BRS Kurumi. Juiz de Fora: Embrapa Gado de Leite, 2015. 4 p. (Embrapa Gado de Leite. Comunicado Técnico, 75). Disponível em: http://ainfo.cnptia.embrapa.br/digital/bitstream/item/124202/1/Informacoes-Tecnicas-sobre-a-cultivar-de-capim-elefante-BRSKurumi-COT-75.pdf

HODGSON, J. Grazing management: Science into practice. Longman Scientific and Technical, Longman Group, London, UK, 1990.

JOCHIMS, F.; DORIGON, C.; PORTES, V. M. O leite para o Oeste Catarinense. Conjuntura. Revista Agropecuária Catarinense. 2018. Disponível em: http://publicacoes. epagri.sc.gov.br/index.php/RAC/article/ view/67/44

LEMAIRE G.; JEUFFROY M.H.; GASTAL, F. Diagnosis tool for plant and crop $\mathrm{N}$ status in vegetative stage. Europ. J. Agrono- my 28, 614-624, 2008. DOI: https://doi. org/10.1016/j.eja.2008.01.005

LEMAIRE G.; GASTAL F. N uptake and distribution in plant canopies. In: LEMAIRE G. (Ed.) Diagnosis of nitrogen status in crops. Heidelberg: Springer-Verlag, 2007. p.3-43.

PARSONS, A.J.; PENNING, P.D. The effect of the duration of regrowth on photosynthesis, leaf death and the average rate of growth in a rotationally grazed sward. Grass Forage Science, v.43, p.15-27, 1988. DOI: https://doi.org/10.1111/j.1365-2494.1988. tb02137.x

PAULINO, V.T.; PAULINO, T.S. Avanços no Manejo de Pastagens Consorciadas. Revista Científica Eletrônica de Agronomia. Ed. 3, Garça - SP, jun 2003.

R Core Team (2016). R: A language and environment for statistical computing. R Foundation for Statistical Computing, Vienna, Áustria.

SENGER, C.C.D.; KOZLOSKI, G.V.; SANCHEZ, L.M.B.; MESQUITA, F.R.; ALVES, T.P.; CASTAGNINO. D.S. Evaluation of autoclave procedures for fibre analysis in forage and concentrate feedstuffs. Animal Feed Science and Technology, v.146, p.169-174, 2008.

SOCIEDADE BRASILEIRA DE CIÊNCIA DO SOLO - Núcleo Regional Sul. Manual de adubação e calagem para os estados do RS e de SC. Comissão de Química e Fertilidade do Solo - RS/SC. 12.ed., Porto Alegre, 2016.

SBRISSIA, A.F.; DUCHINI, P.G.; ZANINI, G.D.; SANTOS, G.T.; PADILHA, D.A.; SCHMITT, D. Defoliation Strategies in Pastures Submitted to Intermittent Stocking Method: Underlying Mechanisms Buffering Forage Accumulation over a Range of Grazing Heights. Crop Science, v.58, p.945-954, 2018. DOI: https:// doi.org/10.2135/cropsci2017.07.0447

TILLEY, J.M.A.; TERRY, R.A. A two-stage technique of the "in vitro" digestion of forage crop. Journal British Grassland Society, v.18, n.2, p.104-111. 1963.

VAN SOEST, P.J.; ROBERTSON, J.B.; LEWIS, B.A. Methods for dietary fiber, neutral detergent fiber, and non starch polysaccharides in relation to animal nutrition. Journal of Dairy Science, v.74, n.10, p.3583-3597, 1991. 